\title{
ANALISIS STRUKTURALIS PADA IKLAN M-BANKING BCA MOBILE DI TELEVISI
}

\author{
Dhika Santhi, Miftahulkhairah Anwar \\ DhikaSanthi9905820002@mhs.unj.ac.id,miftahulkhairah@unj.ac.id \\ Pascasarjana UNJ
}

Diserahkan: 26 Januari 2021, Direvisi: 29 April 2021, Diterima: 22 Juni 2021

\begin{abstract}
This paper is entitled "Structural Analysis on BCA Mobile M-Banking advertisement on Television". The aim of this paper is to shows how a structural perspective on linguistic phenomena in contemporary concepts. Television advertising is a medium that can persuade the public who sees the broadcast. There a lot of advertisements shown on television require ad makers to be more creative and innovative in order to compete. The advertisement that is the subject of research in this paper is the Structural Analysis advertisement on the M-Banking BCA Mobile advertisement on television which lasts 59 seconds. In this paper the authors use several relevant theories, namely: Structuralist, Advertising, M-Banking. The results of this paper found that the BCA Mobile M-Banking advertisement made it easier for the public to do transactions. Well-packaged advertisements have proven to attract a lot of public interest in using M-Banking in this digital age. This advertisement which lasts about 59 seconds is displayed in an attractive and innovative form.
\end{abstract}

Keywords: Structuralist, Advertising, M-Banking 


\begin{abstract}
Abstrak
Tulisan ini berjudul "Analisis Strukturalis pada Iklan M-Banking BCA Mobile di Televisi”. Tulisan ini bertujuan untuk memaparkan bagaimana perspektif struktural terhadap fenomena kebahasaan dalam konsep kekinian. Iklan televisi ini menggambarkan sebuah media yang dapat mempersuasi masyarakat yang melihat tayangan tersebut. Banyak sekali iklan yang ditayangkan di tv, sehingga mengharuskan para pembuat iklan lebih kreatif dan inovatif agar bisa bersaing di industri tersebut. Iklan yang menjadi subjek penelitian pada tulisan ini adalah iklan M-Banking BCA Mobile di televisi yang berdurasi 59 detik. Dalam tulisan ini penulis menggunakan beberapa teori yang relevan, yaitu: strukturalis, iklan, M-Banking. Hasil tulisan ini menemukan bahwa iklan M-Banking BCA Mobile memudahkan masyarakat dalam hal bertransaksi. Iklan yang dikemas dengan apik terbukti menarik banyak minat masyarakat untuk menggunakan $M$-Banking di zaman digital seperti ini. Iklan ini berdurasi sekitar 59 detik yang ditampilkan dengan bentuk sangat menarik dan juga inovatif.
\end{abstract}

Kata Kunci: Strukturalis, Iklan, M-Banking

\title{
PENDAHULUAN
}

Setiap negara di belahan dunia tentu memiliki ciri khas masingmasing baik dari karakter, budaya, kebiasaan, dan bahasa yang digunakan. Bahasa memiliki peranan penting dalam menunjukan identitas suatu bangsa. Oleh karena itu, bahasa disebut sebagai alat pemersatu bangsa, terutama Indonesia yang memiliki keberagaman etnik dan suku. Bahasa Indonesia dapat dijadikan alat untuk berkomunikasi antarsuku yang terdapat di seluruh pelosok nusantara.

Selain untuk berkomunikasi bahasa juga merupakan komponen penting dalam berkehidupan sebagai alat berpikir, mengekspresikan perasaan, kontrol sosial, dan masih banyak lagi. Bahasa memiliki peranan penting dalam ilmu pengetahuan dan pembelajaran seperti linguistik. Linguistik merupakan ilmu yang mempelajari penggunaan bahasa secara mendetail. 
Bahasa itu sangat kompleks, maka diperlukan sebuah kajian untuk mempelajarinya, yakni linguistik. Dalam perkembangannya teori linguistik dipenuhi dengan bermacam aliran salah satunya aliran strukturalisme. Aliran strukturalisme secara garis besar merupakan paham yang memandang bahwa segala sesuatu itu terdiri dari struktur yang tidak dapat terpisah. Jadi hakikatnya bahwa bahasa terdiri antarbagian dan tidak dapat berdiri sendiri.

Istilah paradigma cenderung merujuk ke arah pola atau metode penyelesaian suatu masalah. Adapun, strukturalisme merupakan metode atau sistem yang diperlukan untuk mengkaji ilmu tentang manusia yang bertitiktolak dari prinsip linguistik yang diperkenalkan oleh Saussure. Teori yang mendasari strukturalisme adalah teori tentang bahasa, terutama teori lingusitik modern yang dicetuskan oleh Ferdinand de Saussure pada tahun 1957-1913. Adanya berbagai dialek membuat strukturalisme mulai dibesarkan oleh beberapa filsuf seperti Levi-Strauss, Jacques Lacan dan filsuffilsuf strukturalis yang lain.

Menurut Ferdinand de Saussure (dalam Syukri, 2019) bahasa adalah alat yang digunakan masyarakat untuk berkomunikasi dengan memakai sistem tanda yang maknanya dipahami secara konvensional. Tanda bahasa terdiri dari 2 unsur dan kedua unsur tersebut tidak dapat dipisahkan yaitu significant atau penanda dan signifie atau petanda. Dapat dikatakan juga significant sebagai citra akustik, bentuk atau pattern dan signifie merupakan unsur gagasan dan pemikiran.

Pesan iklan bisa muncul dimana saja dan kapan saja sebagai contoh iklan di radio, tv, internet, di dalam toko, dan nyaris setiap sudut ruangan iklan sering muncul. Dalam urusan penjualan, iklan adalah sesuatu yang berpengaruh sekali sebagai penunjang keberhasilan dari suatu jasa atau produk. Adanya iklan, membuat masyarakat mengenal adanya suatu produk atau jasa yang ditawarkan. Iklan telah menjadi alat atau perantara antara produsen dan konsumen dalam mempromosikan suatu produk atau jasa dalam usaha membagikan informasi ataupun untuk mengajak para konsumen agar tetap menggunakan suatu produk yang diiklankan. 
Ketatnya persaingan dalam industri tersebut mengharuskan suatu perusahaan agar lebih jeli dalam mengamati perkembangan selera konsumen. Perusahaan harus lebih selektif, kreatif serta inovatif dalam melahirkan ide-ide yang dapat menarik minat konsumen. Jika suatu perusahaan tidak dapat melihat kebutuhan pasarnya, itu akan menyulitkan perusahaan tersebut untuk bersaing dalam industri ini. Hal tersebut akan terjadi, jika dilakukan tanpa strategi dan kreatifitas dalam menarik perhatian masyarakat. Para perusahaan berusaha menjadi pemenang dalam persaingan suatu produk yang sama atau sejenis yang dimiliki para pesaingnya (Sidik, 2018).

Persaingan dalam dunia industri memang sangatlah ketat hingga membuat perusahaan berlomba agar tetap bisa eksis. Salah satu jalan yang sering digunakan adalah lewat iklan. Iklan merupakan salah satu cara berdagang untuk menawarkan suatu produk atau jasa kepada khalayak lewat suatu media yang diyakini dapat mempersuasi masyarakat agar memakai produk atau jasa yang ditawarkan, memberikan informasi, dapat juga untuk memberikan citra baik suatu produk (Triadi \& Bharata dalam Haryadi, 2019).

Dalam pembuatan iklan dimulai dengan mengidentifikasi faktor yang berkaitan dengan target pasar. Dalam hal ini, unsurunsur yang bersifat sosiologis, psikologi dan ekonomi konsumen sebagai bahan dasar pertimbangan dalam proses kreatif pembuatan suatu iklan. Semakin cepatnya perkembangan teknologi komunikasi mengharuskan content creator iklan harus lebih inovatif dan bervariatif lagi.

Bermacam bentuk pesan mengenai suatu produk atau jasa kebanyakan disampaikan melalui iklan. (Dyck, 1992) mengutarakan bahwa suatu iklan adalah sebuah dunia i sihir yang bisa merubah suatu komoditi menjadi sesuatu yang menarik dan menakjubkan. Banyak iklan dari media cetak atau elektronik condong mempertunjukkan suatu budaya yang instan. Secara universal iklan kini telah menjadi tren, produsen dan kreator iklan diberikan kesempatan untuk melakukan survei terhadap konsumen sesuai dengan sasaran pasarnya. Terbukti pada perkara pengeksplorasian 
konsumen terdapat beberapa industri yang meletakkan fokusnya terhadap iklan. Karena penting sekali untuk menetapkan kelanjutan dari suatu produk yang akan dihasilkan. Salah satunya adalah produk teknologi kekinian, dalam hal ini yang dimaksud adalah produk $M$-Banking. Dunia perindustrian berupa produk teknologi akan terus berkembang mengikuti zaman.

Pemakaian TIK dalam dunia bank dinilai lebih maju daripada sektor yang lain. Berbagai jenis teknologi di antaranya Automatic Teller Machine (ATM), Banking Application System, Real Time Gross Settlement System, Sistem Kliring Elektronik dan Mobile Banking (Fadlan, 2018).

Di zaman sekarang ini teknologi merupakan salah satu bidang yang berkembang dengan cepat. Kemajuan teknologi membuat berbagai hal semakin canggih dan semakin mudah, salah satunya dalam urusan bertransaksi. Di era sekarang ini dalam hal bertransaksi masyarakat lebih memilih menggunakan alat pembayaran M-Banking karena dianggap lebih mudah dan praktis atau yang lebih dikenal dengan cashless.

Fasilitas M-Banking dapat membuat masalah nasabah yang menginginkan layanan cepat, nyaman, dan tersedia 24 jam nonstop dapat diakses dari mana saja cukup melalui handphone. Fasilitas yang ditawarkan $M$-Banking antara lain cek saldo, mutasi rekening, transfer sesama bank atau beda bank, pembayaran tagihan (Rahayu, 2017).

Iklan yang ditayangkan di tv, terlihat dengan jelas bagaimana mudahnya melakukan pembayaran, melakukan transfer dengan sangat mudah hanya dengan klik pada aplikasi $M$-Banking $B C A$ Mobile. Menurut paparan diatas penulis tertarik untuk menganalisis tentang "Analisis Strukturalis pada Iklan M-Banking BCA Mobile di Televisi".

Menurut paparan pada latar belakang diatas tersebut, maka dapat rumusan masalah sebagai berikut: Bagaimanakah analisis strukturalis pada iklan M-Banking BCA Mobile di televisi?. Analisis ini bertujuan mengetahui analisis strukturalis pada iklan M-Banking BCA Mobile di televisi. 


\section{KAJIAN LITERATUR}

\section{Teori Strukturalisme Menurut Ferdinand de Saussure}

Dalam perkembangannya bahasa tentu memiliki sejarah, dimulai dari zaman Yunani Kuno linguistik berkembang dengan hadirnya berbagai macam aliran, pendekatan, dan paham yang berbeda-beda. Salah satu aliran tersebut ialah strukturalisme. Menurut Keraf (dalam Suryani \& Semi, 2014) suatu struktur dapat terlihat dari berbagai sudut pandang. Sesuatu dapat dibilang memiliki struktur apabila mempunyai bagian yang secara fungsional berkorelasi satu dengan yang lain. Bagian tersebut tergantung dengan cara melihat barang tersebut. Adapun pendapat Chaer (dalam Efendi, 2012) bahwa linguistik strukturalis mencoba menjabarkan suatu bahasa dilihat dari sifat atau ciri khas yang ada pada bahasa tersebut.

Bahasa dalam strukturalisme dapat dimengerti sebagai sistem tanda yakni relasi yang terjadi antara penanda atau aspek material dan petanda, yaitu aspek mental atau konseptual dari tanda. Relasi keduanya bersifat arbiter, berdasarkan pengguna bahasa tersebut (Karnanta, 2015).

Dapat disimpulkan bahwa strukturalisme mempunyai ciri khas yang dimiliki bahasa diantaranya yaitu konvensional dan sistematis. Hal ini menegaskan bahwa bahasa terbentuk dari kesepakatan masyarakat yang menggunakan bahasa tersebut. Oleh karena itu, bahasa harus memiliki struktur yang teratur dan jelas.

\section{Ferdinand de Saussure}

Pada abad ke 17 dan 18 muncul revolusi Perancis yang melahirkan kesadaran tentang eksistensi manusia secara politik. Revolusi industri yang mengungkapkan peranan dan sumbangan ilmu pengetahuan bagi kesejahteraan manusia. Searah dengan revolusi ini, timbul problematika yang meragukan ilmu bahasa yang mapan. Suatu ilmu yang mapan memiliki corak penalaran yang khas sesuai dengan substansi alamiah yang dikaji, dan diharapkan memiliki syarat ontologis yang layak, sebagai berikut.

Ilmu mapan : objek penelitian

permasalahan 


\section{metodologi \\ generalisasi \\ sistematika}

Tantangan ini dijawab oleh Ferdinand de Saussure yang menyatakan bahwa ilmu bahasa merupakan ilmu yang berdiri sendiri secara ontologis dan epistemologis. Ontologis membahas tentang sesuatu yang ingin diketahui, sedangkan epistemologis membahas mengenai bagaimana cara memperoleh pengetahuan.

Saussure memfokuskan adanya ciri yang dapat dikatakan sebagai faktor untuk mengetahui kemajuan yang ada pada teori modern atau kontemporer. Pertama, Saussure meninjau tanda linguistik yang berciri arbiter, yaitu tidak adanya korelasi antara penanda dan petanda. Kedua, Saussure menegaskan jika sebuah tanda adalah sesuatu yang berbeda yang mana disebut sebagai sistem makna yang telah mendapat signifikansinya.

Pokok pikiran yang sangat utama dari Saussure mengenai strukturalisme adalah:

1. Diakronik dan sinkronik,

2. Langue dan parole.

3. Penanda dan petanda.

Saussure (1873) menempatkan tanda dalam bahasan komunikatif manusia. Kemudian dilakukan seleksi antara apa yang dimaksud dengan signifier atau penanda dan signified atau petanda. Sederhananya penanda adalah suatu bunyi yang mempunyai makna sehingga dapat disebut dengan aspek material. Pengertian aspek material itu sendiri adalah apa yang dikatakan dan apa yang ditulis ataupun sesuatu yang dibaca. Sementara itu signified adalah sebuah refleksi psikologis, yaitu sebuah pikiran atau konsep dari bahasa.

Saussure membedakan persepsi antara simbol dan sign. Bagi Saussure simbol tidak semuanya selalu arbitrer, banyak simbol yang terkait dengan maknanya, sebagai contoh simbol keadilan yang dilambangkan dengan timbangan. Secara global, sign memang bersifat arbiter. Menurut Saussure, kata-kata tidak pernah menjadi materi organik dari sistem linguistik dan jumlahnya lebih kecil dari yang diperkirakan. 
Dari pandangan-pandangan tersebut dapat diartikan bahwa Saussure lebih mengacu bagaimana penggunaan bahasa dapat merepresentasikan antara satu dengan yang lainnya, jadi bahasa tidak bisa berdiri sendiri. Saussure juga lebih melihat bahasa sebagai sesuatu yang arbiter antara suatu bunyi dan makna yang dimiliki.

Strukturalisme merupakan kaidah filsafat yang menjadi landasan suatu paham pada era ini. Adapun linguistik adalah ilmu yang sistematik dalam bidang humaniora yang mana Saussure sudah menempatkan dasar linguistik modern. Ada tiga pembeda yang diperkenalkan oleh Saussure dalam strukturalisme yaitu significant dan signifie, language, parole dan langue dan yang terakhir adalah sinkronik dan diakronik. Suatu ide atau konsep tidak bisa lepas dari tanda Bahasa tetapi termasuk kedalam tanda Bahasa itu sendiri.

Penanda (signifiant) adalah bunyi yang bermakna. Significant adalah aspek material bahasa, yaitu apa yang dikatakan atau didengar dan apa yang ditulis atau dibaca. Yang ditandakan (signifie) adalah gambaran, ide, pikiran atau konsep. Signifie adalah aspek mental dari bahasa. Tanda dan bahasa selalu mempunyai bentuk atau pattern yaitu significant dan signifie. Jika significant tanpa signifie itu tidak ada artinya karena itu bukan merupakan suatu tanda. Sebaliknya, suatu signifie tidak mungkin dapat tersampaikan atau ditangkap jika lepas dari significant.

Bahasa individu yang digunakan secara umum dikatakan sebagai langage. Langage dibedakan menjadi 2 yaitu langue dan parole. Parole adalah pemakaian bahasa secara individu. Parole tidak dipelajari dalam linguistik. Linguistik juga melihat ada unsur lain dari langage yaitu langue, langue merupakan suatu tinjauan bahasa yang didalamnya terdapat kaidah-kaidah dan telah menjadi konvensi.

Bahasa dapat dipelajari menurut dua sudut yaitu sinkronik dan diakronik, sinkronik berarti "bertepatan menurut waktu" dan diakronik "menelusuri waktu”. Diakronik yakni suatu bidang ilmu yang tidak cuma bisa dikerjakan sesuai dengan kemajuannya, tetapi juga dapat memakai struktur yang sama. 
Ciri khas strukturalisme adalah berpusat pada penjabaran keadaan sasaran objek lewat pengamatan karakteristik unsur intrinsik yang tidak terikat oleh waktu Berangkat dari seperangkat fakta yang diamati pada awalnya, strukturalisme menyikapi dan menggambarkan struktur inti dari suatu objek dan lebih lanjut menciptakan suatu model teoritis dari objek tersebut.

Suatu tanda bahasa menunjukkan benda dalam kehidupan nyata, tetapi bagi Saussure suatu tanda yang bermakna bukan lagi hanya tentang apa yang dilihat saja tetapi ada konsep dari pemaknaan tersebut. Secara popular kita mencari konsep yang sebenarnya sudah bermakna. Makna tidak dapat dipisahkan dari kata karena suatu kata bukan hanya ada bunyi atau hanya sesuatu yang ditulis.

Oleh karena itu, menurut Saussure tanda bahasa yang dipelajari dalam linguistik terdiri atas dua unsur yaitu significant dan signifie. Dalam bahasa Indonesia dapat diterjemahkan menjadi: "penanda" dan "yang ditandakan". Significant adalah bunyi yang mempunyai makna. Signifie adalah gambaran, pikiran atau konsep. Dalam tanda bahasa kedua unsur tersebut tidak dapat dipisahkan.

Dalam pembahasan tentang prinsip-prinsip linguistic yang dikemukakan Saussure ada istilah struktur yang tidak dipakai. Setelah Saussure, banyak ahli yang menggunakan istilah struktur tersebut dalm linguistik. Pendekatan struktural mengenai bahasa memperoleh arti sebagai pendekatan yang mengakui bahasa sebagai suatu sistem.

\section{Iklan}

Klepper et al (n.d.) adalah seorang ahli yang berjasa dalam meninjau tentang istilah periklanan atau advertising. Pada buku berjudul Advertising Prosedure di sana terdapat istilah advertising yang berasal dari bahasa Latin yaitu ad-vere artinya mengalihtugaskan konsep serta ide kepada kelopmpok yang lain. Lalu paparan seperti ini tidak ada perbedaannya dengan yang dimaksud dengan komunikasi. Kata iklan diartikan dalam KBBI sebagai suatu berita untuk mempersuasi atau mendorong masyarakat mengenai suatu jasa atau benda yang ditawarkan melalui media massa seperti koran, televisi, radio. 
Periklanan selalu berkembang sangat pesat dari waktu ke waktu dalam bidang ekonomi dan dunia industri. Dengan menggunakan sistem penanganan yang lumayan baik, iklan sudah mempersembahkan suatu jasa reproduksi komoditi yang sangat besar untuk perkembangan dunia industri. Ketika iklan mulai dikenal dalam lingkungan masyarakat, iklan-iklan tersebut kebanyakan masih berbentuk ukiran atau iklan koran. Oleh karena itu kemajuan sebuah iklan mengikuti alur perkembangan media masa pada waktu itu. Oleh sebab itu, iklan yang muncul pertama kali masih berupa relief kemudian lama-kelamaan berubah menjadi iklan koran dan papan nama. Kemudian berkembang lagi menjadi iklan radio dan saat ini iklan disiarkan melalui tv dan internet sehingga dapat ditemui dimanapun dalam berbagai bentuk.

Untuk meninjau sebuah iklan dengan menggunakan perspektif strukturalis, dapat dilakukan dengan cara meninjau sistem tanda bahasa dalam iklan tersebut. Iklan menggunakan sistem tanda yang berupa suatu lambang, baik yang berupa verbal ataupun ikon. (Barthes, 1994) menganalisis iklan yang isinya berupa pesan lingustik, pesan ikonik yang hanya bisa berfungsi jika digabungkan dengan sistem tanda dan pesan ikonik yang tak terkodekan. Lambang verbal adalah bahasa yang dikenal. Lambang nonverbal adalah warna dan bentuk yang diperlihatkan di dalam iklan yang secara tidak langsung meniru visual atas bentuk aslinya.

Analisis strukturalis iklan terdiri atas lambing baik verbal maupun nonverbal. Dalam menganalisis iklan, ada beberapa hal yang harus dipertimbangkan, sebagai berikut:

a. Penanda dan petanda.

Penanda menggambarkan aspek material dari bahasa yaitu sesuatu yang dikatakan atau didengar dan sesuatu yang ditulis atau dibaca. Penanda bisa berupa bunyi yang bermakna. Adapun petanda adalah suatu konsep atau gagasan dari penanda.

b. Gambar, indeks, simbol.

Gambar adalah pertemuan antara titik, garis, warna yang dikreasikan dengan tujuan untuk merepresentasikan sesuatu. 
Indeks adalah sebuah tanda yang mensubtitusi sumber tumpuan dengan cara mengaitkannya secara eksplisit atau implisit dengan sumber tumpuan yang lainnya. Simbol adalah suatu tanda yang mewakili objeknya melalui kesepakatan dalam konteks spesifik, biasanya makna-makna sosial dalam sebuah simbol telah disepakati oleh masyarakat melalui tradisi historisnya.

c. Fenomena sosiologi.

Fenomena sosiologi adalah model atau orang yang berada di dalam iklan, serta orang-orang yang menjadi sasaran iklan, di mana mereka merefleksikan kelas sosial ekonomi, gaya hidup (life style) dan sebagainya.

d. Publikasi.

Publikasi adalah suatu langkah penerbitan iklan yang diperuntukkan bagi public atau umum.

\section{M-Banking}

Pada era sekarang ini teknologi telah mendigitalisasikan banyak hal. Salah satunya adalah layanan bank yang sepertinya wajib dimiliki oleh para pengguna smartphone, yakni M-Banking atau mobile banking. Adanya M-Banking ini, masyarakat bisa melakukan transaksi kapanpun dan dimanapun tanpa dibatasi oleh waktu dan juga tempat. Fungsi $M$-Banking diantaranya adalah transfer, pembelian pulsa dan token listrik, isi ulang dompet digital seperti Dana, OVO, Gopay, ShopeePay, pembayaran asuransi kesehatan pun dapat dilakukan lewat mobile banking.

Menurut Lifepal.co.id M-Banking adalah sebuah fasilitas untuk melaksanakan bermacam-macam transaksi yang ditawarkan oleh pihak bank. Oleh karena itu, harus mengunduh layanan mobile tersebut di smartphone. Registrasinya dapat dilakukan secara mandiri dengan mengikuti langkah aplikasi tersebut. Dengan mobile banking semua dapat melakukan bermacam transaksi keuangan seperti transaksi di ATM. Mulai dari transfer, token listrik, isi pulsa, sampai pembayaran yang lain kapan saja dan dimana saja. Misalnya untuk melakukan pembayaran asuransi kesehatan agar tidak terlupa dan 
polis diberhentikan. Itulah alasan orang-orang yang menentukan untuk menggunakan M-Banking.

\section{METODE PENELITIAN}

Penelitian ini merupakan penelitian deskriptif kualitatif, sehingga tidak menggunakan angka numerik, seperti pada jenis wawancara tertentu. Metode ini dianggap bersifat interpretatif (Saha et al, 2006). Tulisan ini menggunakan kajian strukturalis dari teori Ferdinand de Saussure untuk menganalisis makna yang terdapat dalam suatu teks.

Subjek penelitian dalam penelitian ini adalah iklan M-Banking BCA Mobile di televisi yang menampilkan seorang suami yang masih lembur di kantor dan mendapat pesan dari istrinya untuk ditrasnfer sejumlah uang. Saat melihat pesan tersebut sang suami bingung namun seketika berubah tersenyum saat mengingat ada M-Banking BCA Mobile yang menjadikan urusan transfer menjadi mudah dan efisien waktu. Teknik Pengumpulan data yang dilakukan dalam penelitian ini adalah penelitian kepustakaan dan pengamatan langsung.

\section{HASIL PENELITIAN DAN PEMBAHASAN}

Analisis strukturalis menggunakan teori dari Ferdinand de Saussure merupakan langkah dalam menerjemahkan gambar suatu iklan, yaitu iklan M-Banking BCA Mobile. Fenomena bahasa atau bisa disebut fenomena komunikasi secara konvensional dikatakan dengan istilah langage, maka di dalamnya terkandung dua konsep lagi, yaitu parole dan langue. Strukturalisme terhadap contoh kebahasaan dalam konteks kekinian terdapat pada kalimat "tinggal tap". Pendekatan strukturalisme dari teori Saussure melihat ada pemaknaan bahasa dari kalimat yang dilontarkan oleh masyarakat tersebut dan menjadi kekinian. Strukturalis melihat adanya telaah diakronik, signifiant, signifie.

Proses strukturalis dalam iklan M-Banking BCA Mobile menggunakan scene untuk mendapatkan makna bahasa. Dalam iklan tersebut terlihat bahwa ada seorang laki-laki yang sedang lembur dan 
mendapat pesan dari sang istri yang meminta untuk di transferan sejumlah uang. Sang suami terlihat kebingungan karena hari sudah gelap dan dia masih harus lembur untuk menyelesaikan pekerjaan ditambah lagi harus mencari mesin atm di luar kantor, tetapi sesaat kemudian sang suami teringat dengan aplikasi M-Banking BCA yang memudahkan dalam urusan bertansaksi.

Telaah diakronik terdapat pada detik ke-25 yaitu "lagi seruserunya seret kuota, untungnya tinggal top up aja". Pada kalimat tersebut terdapat makna bahwa jaman sekarang berbeda dengan dulu, untuk membeli kuota tidak perlu lagi pergi ke counter tetapi tinggal klik top up di M-Banking BCA Mobile.

Penanda dalam iklan M-Banking BCA Mobile ini adalah segala sesuatu yang mempunyai makna yang dapat berupa suara, tulisan, body language, property ataupun setting. Untuk lebih jelasnya berikut penanda dalam iklan M-Banking BCA Mobile:

- Penanda berupa suara pesan dari sang istri, orang bernyanyi, bunyi instrumen musik.

- Penanda berupa tulisan meliputi tulisan pesan dari sang istri, BCA Keyboard (info saldo, transfer, mutasi rekening, transfer berhasil), Blokir Kartu ATM (nomor Admin), M-Commerce (beli paket data, nomor ponsel, nominal pembelian), ATM BCA setor tunai, BCA Mobile Banking.

- Penanda yang berupa body language meliputi adegan laki-laki duduk sambil melihat ponselnya, adegan seorang perempuan sedang bernyanyi diiringi pemain musik, adegan orang-orang sedang berada dalam sebuah pesta dan ada sorang ibu yang menekan tombol blokir pada aplikasi BCA Mobile Banking, adegan anak-anak muda sedang melakukan tarian korea dan ada seorang remaja perempuan sedang duduk sambil membeli paket kuota internet lewat $m$-commerce pada aplikasi $B C A$ Mobile Banking, adegan seorang pria membawa 2 kantong tas berisi uang dan datang 3 orang laik-laki membawa mesin ATM setor tunai BCA, adegan semua orang berkumpul melakukan flash mob.

- Penanda yang berupa property meliputi aktor sedang duduk 
di ruangan kantor, wanita menyanyi di panggung, wanita yang berada diruang pesta, anak-anak muda yang sedang menari di ruang dance, laki-laki di jalan menuju ATM, semua orang berada di halaman luar melakukan flash mob.

- Penanda yang berupa adegan wanita bernyanyi, orang-orang melakukan pesta, anak-anak muda melakukan tarian, semua orang berkumpul melakukan flash mob.

- Penanda yang berupa setting meliputi tampilan confetti jatuh berterbangan ketika orang-orang berada di sebuah pesta dan ketika semua orang melakukan flash mob.

Jadi dari uraian di atas, pada bagian significant (penanda) dalam konteks kekinian ditandai pada "tinggal tap". Kata "tinggal tap" dianggap menunjuk kepada sebuah kartu atau aplikasi yang ada di dunia nyata. Padahal kata tersebut sebenarnya merujuk pada sebuah konsep yang ditandai sebagai "tap".

Sementara itu petanda merupakan gambaran/ide, sehingga dapat dikatakan bahwa petanda adalah bagian dari suatu bahasa. Sebuah tanda dibuat dari penanda dan petanda. Penanda tidak ada artinya dan karena itu tidak merupakan tanda. Sebaliknya, petanda tidak memungkinkan untuk dikatakan terlepas dari penandanya.

Dengan dikenalkannya bahasa sebagai "tanda" oleh Saussure, berarti ilmu kebahasaan telah menemukan suatu objek yang pasti, yakni bahasa sebagai tanda. Bahasa tidak lagi ditafsirkan secara historis, namun sebagai sebuah tanda yang merujuk kepada hal yang lain. Signifie dalam iklan M-Banking BCA Mobile adalah konsep dari M-Banking itu sendiri yang mengubah sistem transaksi menjadi lebih mudah dari cash menjadi cashless.

Penggunaan M-Banking sebagai sarana untuk pembayaran dan pembelian suatu barang atau jasa dianggap lebih efisien daripada harus membawa uang ataupun harus mengambil dulu ke mesin atm. "Bayar pakai M-Banking, tinggal tap." Pemaknaan dalam strukturalis pada kata "tinggal tap" adalah bentuk kemudahan dalam bertransaksi. 
Strukturalis Saussure memandang fenomena bahasa "tinggal tap" sebagai konteks kekinian yang berarti cashless atau tidak diperlukan lagi uang tunai sebagai alat pembayaran. Hal itu didefinisikan oleh hampir semua orang yang menggunakan istilah "tinggal tap". Bahasa individu ini menggambarkan rancangan dari suatu produk dari gagasan dan action untuk membentuk suatu pattern secara global dan menghasilkan realita sosial. Tinggal tap tidak hanya merujuk pada benda yang berupa kartu tetapi juga ada maknanya yang berarti pembayaran nontunai atau zaman sekarang kita menyebutnya cashless.

\section{PENUTUP}

Sebuah karya sastra yang terbangun atas fondasi bahasa, mempunyai karakteristik berupa bentuk/form dan isi/content dan juga makna/significante yang otonom. Hal ini berarti suatu penafsinaran karya sastra bisa dikaji dari teks sastra itu sendiri. Memang suatu penafsiran tersebut dapat mengaitkan kebertautan antar unsur pembangun karya sastra. Kebertautan unsur itu akan membentuk sebuah makna yang utuh. Bahasan tersebut dapat juga untuk menambah wawasan terhadap aliran linguistik. Dari pembahasan di atas maka dapat diambil pemahaman dan kesimpulan mengenai teori strukturalis yang didalamnya terdapat penanda dan petanda. Dalam era digitalisasi ini Iklan-iklan yang berkembang saat ini banyak yang menggunakan makna tersirat dengan tampilan sangat apik, inovatif dan kreatif. Cara pandang strukturalis dalam bahasa kekinian menunjukkan bahwa bahasa berubah seiring dengan perkembangan zaman. Didukung dengan kemajuan teknologi, bahasa akan lebih cepat berkembang.

\section{DAFTAR PUSTAKA}

Barthes, R. (1994). The Semiotic Challenge. Barkeley: Univ of California Press.

Dyck, I. (1992). William Cobbett and Rural Popular Culture. Cambridge: Cambridge University Press. 
Efendi, M. S. (2012). Linguistik Sebagai Ilmu Bahasa. Jurnal Perspektif Pendidikan, 5(1), 97-101.

Fadlan, A. (2018). Pengaruh Persepsi Kemudahan dan Persepsi Kegunaan Terhadap Penggunaan Mobile Banking (Studi pada Mahasiswa Pengguna Mobile Banking Universitas Brawijaya). Director, 15(40), 6-13.

Haryadi, T. (2019). Analisis Iklan Televisi Sampoerna Hijau Versi "Es Kacang Ijo" Dengan Pendekatan Semiotika Roland Barthes. Jadecs, 1, 1-16.

Karnanta, K. Y. (2015). Struktural (dan) Semantik: Teropong Strukturalisme dan Aplikasi Teori Naratif AJ Greimas. Atavisme: Jurnal Ilmiah Kajian Sastra, 18(2), 171-181.

Klepper, O. H., Anderson, T. D., Ashworth, J. A., Moscati, A. F., Erdmann, R. C., Kylstra, C. D., ... Mills, C. B. (n.d.). Preface: Fusion Reactor Materials: 1973 ANS Winter Meeting (Robert J. Teitel).

Rahayu, I. S. (2017). Minat Nasabah Menggunakan Mobile Banking dengan Menggunakan Technology Acceptance Model (ATM): Studi Kasus PT Bank Syariah Mandiri Cabang Yogyakarta. JESI (Jurnal Ekonomi Syariah Indonesia), 5(2), 137. https://doi. org/10.21927/jesi.2015.5(2).137-150

Saha, S Nadiga, S Thiaw, C Wang, J Wang, W Zhang, Q Van den Dool, H M Pan, H-L Moorthi, S. B. (2006). The NCEP climate forecast system. Journal of Climate, 19(15), 3483-3517.

Saussure, F. De. (1873). Course in General Linguistics. Language.

Sidik, A. (2018). AnalisisIklan ProdukShampoo PanteneMenggunakan

Teori Semiotika Pierce. Technologia: Jurnal Ilmiah, 9(4), 201. https://doi.org/10.31602/tji.v9i4.1533

Suryani, L., \& Semi, A. (2014). Kemampuan Menulis Narasi Siswa Kelas VII MTsN 1 Kampung Dalam Kabupaten Padang Pariaman. Jurnal Fakultas Keguruan dan Ilmu Pendidikan, 3(6).

Syukri, M. (2019). Analisis Dikotomi Perspektif Ferdinand de Saussure serta Ervin Goffman dalam Kajian Strukturalisme dan Positivisme Pragmatik. Pendidikan Dasar Dan Keguruan, 4(2), $53-62$. 